\title{
Outcomes of Balloon Angioplasty and Stenting for Symptomatic Intracranial Atherosclerotic Stenosis at a High Volume Center
}

\author{
Toshihiro Ueda, Tatsuro Takada, Noriko Usuki, \\ Satoshi Takaishi, Yoshiaki Tokuyama, Kentaro Tatsuno, \\ Yuki Hamada, and Tomohide Yoshie
}

\section{Introduction}

Intracranial atherosclerotic stenosis is an important etiological factor for cerebral infarction, and its incidence is reportedly high in Asians [1]. According to the Japanese Stroke Databank 2015, intracranial atherosclerotic stenosis was observed in approximately 18\% of patients with cerebral infarction. For medical treatment of symptomatic intracranial atherosclerotic stenosis, antiplatelet drugs are primarily used, but the recurrence rate is high and the annual incidence of cerebral infarction is approximately 10\% [2] (Figs. 1 and 2).

Regarding neuroendovascular treatment for intracranial atherosclerotic stenosis, the usefulness of balloon angioplasty was reported following the development of balloon catheters for the intracranial cerebral blood vessels in the early 1990s [3, 4]. Thereafter, the development of intracranial stents was promoted, and the results of a randomized controlled trial of Stenting and Aggressive Medical Management for Preventing Recurrent Stroke in Intracranial Arterial Stenosis (SAMMPRIS) showed that aggressive medical management was superior to angioplasty and stenting with the use of the Wingspan stent system. Indeed, the 30 -day rates of stroke and death were $14.7 \%$ (10.2\% ischemic, $4.5 \%$ hemorrhagic) with stenting versus $5.8 \%$ with aggressive medical management. However, even in the medical management group, the risk is high. When the perioperative strokes were excluded, the rates of subsequent ischemic strokes were almost the same in the two groups.

T. Ueda $(\bowtie) \cdot$ T. Takada $\cdot$ N. Usuki $\cdot$ S. Takaishi $\cdot$ Y. Tokuyama

K. Tatsuno $\cdot$ Y. Hamada $\cdot$ T. Yoshie

Department of Strokology, Stroke Center, St. Marianna University

Toyoko Hospital, Kawasaki, Japan

e-mail: toshiueda-nsu@umin.net; takada-ta@keijinkai.or.jp;

nohtani@marianna-u.ac.jp; s2takaishi@marianna-u.ac.jp;

hsmtoku555@marianna-u.ac.jp; tatsuno.kentaro@marianna-u.ac.jp;

tomohide.yoshie.1215@marianna-u.ac.jp
On the other hand, in Japan, the Wingspan stent was approved in July 2014, and it has been increasingly used. In this study, we retrospectively compared the results of neuroendovascular treatment for symptomatic intracranial atherosclerotic stenosis before and after Wingspan stent approval at our hospital.

\section{Materials and Methods}

At our hospital, 256 sessions of neuroendovascular treatment were performed for 217 patients with symptomatic intracranial atherosclerotic stenosis between 1999 and 2017. This treatment was indicated for patients meeting the following conditions: (1) $\geq 70 \%$ stenosis, (2) a history of cerebral infarction or repeated transient ischemic attacks (TIAs), and (3) written informed consent obtained from the patient or his/her family. Furthermore, acute-phase patients within three days after the onset of cerebral infarction were excluded. In addition, indication criteria for a Wingspan stent in Japan include: (1) emergency treatment for vascular dissection or acute/impending occlusion during angioplasty and (2) additional treatment after angioplasty under circumstances in which there is no other effective treatment method.

The subjects were divided into two groups: early-phase (from August 1999 until June 2014, before Wingspan stent approval) and late-phase (from July 2014 until December 2017, after Wingspan stent approval) groups. We compared initial treatment results and perioperative complications within 30 days after treatment between the two groups. In the late phase, we also examined restenosis and recurrent cerebral ischemic events.

Neuroendovascular treatment was performed under local/intravenous anesthesia. For femoral artery puncture, a 6-F guiding sheath or 8-F guiding catheter was used. As the stenotic blood vessel-dilating procedure, 

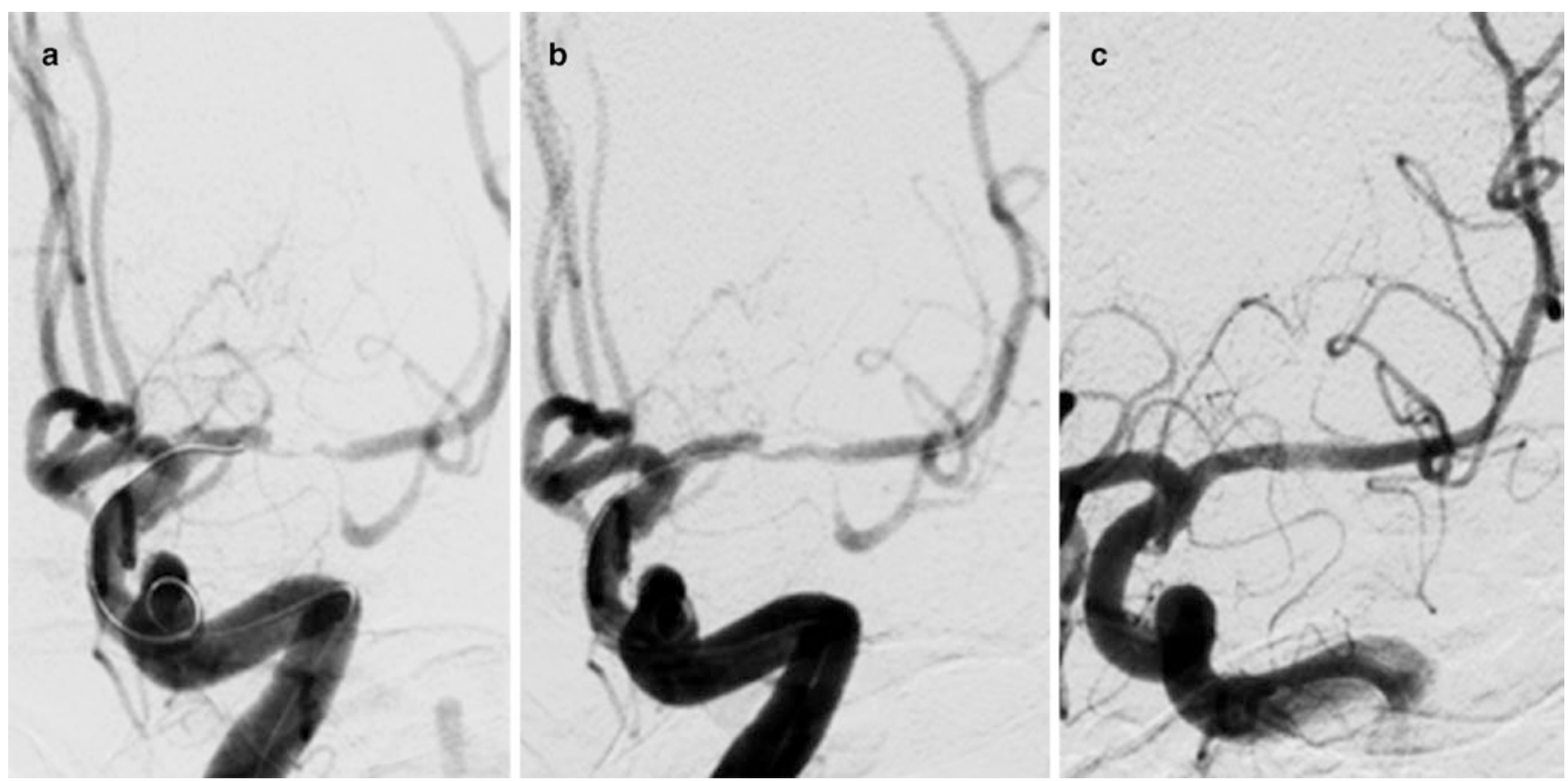

Fig. 1 A 73-year-old patient with a history of minor stroke and recurrent right hemispheric transient ischemic attacks under double antiplatelet therapy. (a) Angiography demonstrates high-grade stenosis of

the left middle cerebral artery. (b) Residual stenosis after balloon angioplasty. (c) Widening of the lumen after deployment of the Wingspan stent
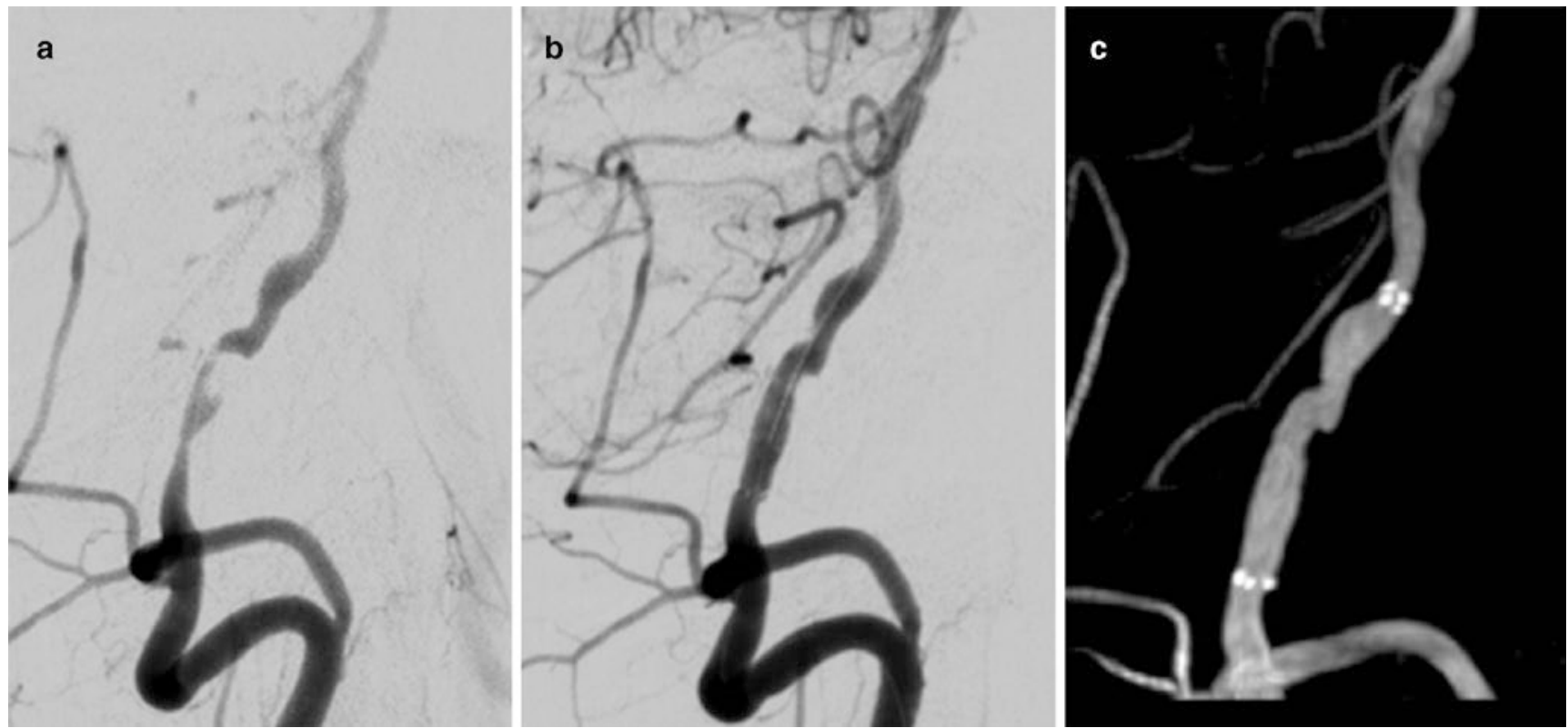

Fig. 2 A 68-year-old patient with recurrent brain stem and cerebellar infarction under double antiplatelet therapy. (a) Angiography shows high-grade stenosis of the left vertebral artery. (b) After balloon angio-

plasty and deployment of the Wingspan stent, there is minimal residual stenosis. (c) The radio-opaque stent end-makers are well visualized balloon angioplasty alone was performed for initial treatment, as a rule. For balloon angioplasty, dilation at $6 \mathrm{~atm}$ at maximum was conducted for 60-90 s using a balloon catheter measuring $1.5-4.0 \mathrm{~mm}$ in diameter (Gateway balloon catheter, Stryker, Maple Grove, MN, U.S.A. or Unryu balloon catheter, Kaneka Medics,
Tokyo, Japan). When dilation after balloon angioplasty was insufficient or when acute occlusion related to vascular dissociation occurred, a stent for the coronary artery was used in the early phase and a Wingspan stent (Stryker, Maple Grove, MN, U.S.A.) was used in the late phase for treatment. 
Two antiplatelet drugs were administered for 1 week prior to treatment. Two-drug administration was continued for 1 month after surgery for patients who underwent balloon angioplasty, and for 6 months to 1 year after surgery for those who underwent stenting. Subsequently, this therapy was switched to monotherapy. Magnetic resonance imaging (MRI) was performed before treatment and within 3 days after treatment. In the late-phase group, cerebral angiography was conducted 6 months after treatment if possible.

\section{Results}

In the early phase, 188 sessions of treatment were performed for 163 patients (mean age: $63.5 \pm 10.2$ years, 125 males). In the late phase, 68 sessions of treatment were performed for 54 patients (mean age: $66.4 \pm 13.3$ years, 45 males) (Table 1 ). In the early phase, the treatment procedures consisted of balloon angioplasty for 157 patients (83.5\%) and stenting for 31 (16.5\%). In the late phase, the former was selected for 33 patients (48.5\%) and the latter for 35 (51.5\%); the number of patients treated by stenting increased. In the early phase, the internal carotid, middle cerebral, basilar, and vertebral arteries were treated in 46, 77, 19 and 21 patients, respectively. In the late phase, they were treated in $19,18,5$, and 11 patients, respectively.

The initial success rates of balloon angioplasty and stenting were $96 \%$ and $100 \%$, respectively. Patients with a percent stenosis of $\leq 50 \%$ were regarded as achieving successful results. In the late phase, Wingspan stents were used in 14 patients with internal carotid artery stenosis, in eight with middle cerebral artery stenosis, in three with basilar artery stenosis, and in 12 with vertebral artery stenosis.

Perioperative complications related to treatment within 30 days consisted of minor stroke in six patients $(3.2 \%)$ (peripheral embolism: three patients, penetrating vessel infarction: two patients and cerebral infarction related to vascular dissociation: one patient) and major stroke in three

Table 1 Comparison of patient characteristics between early and late phases

\begin{tabular}{l|l|l|l}
\hline & Early-phase & Late-phase & Total \\
\hline$N$ & 163 & 54 & 217 \\
\hline Procedures & 188 & 68 & 256 \\
\hline Balloon angioplasty & 157 & 33 & 190 \\
\hline Stenting & 31 & 35 & 66 \\
\hline Age, mean \pm SD, years & $63.5 \pm 10.2$ & $66.4 \pm 13.3$ & \\
\hline M/F & $125 / 38$ & $45 / 9$ & \\
\hline Artery, $N$ (procedures) & & & \\
\hline ICA & $46(53)$ & $19(24)$ & $65(77)$ \\
\hline MCA & $77(88)$ & $18(23)$ & $95(111)$ \\
\hline BA & $19(23)$ & $5(6)$ & $24(29)$ \\
\hline VA & $21(24)$ & $11(15)$ & $32(39)$ \\
\hline
\end{tabular}

Table 2 Comparison of complications within 30 days after the procedure between early and late phases

\begin{tabular}{l|l|l|l}
\hline & Early-phase & Late-phase & Total \\
\hline $\begin{array}{l}\text { Complications within } \\
\text { 30 days }\end{array}$ & & & \\
\hline Minor stroke/TIA & $6(3.2 \%)$ & $2(2.9 \%)$ & $8(3.1 \%)$ \\
\hline Major stroke & $3(1.6 \%)$ & $1(1.5 \%)$ & $4(1.8 \%)$ \\
\hline Total & $9(4.8 \%)$ & $3(4.4 \%)$ & $\begin{array}{l}12 \\
(4.7 \%)\end{array}$ \\
\hline
\end{tabular}

(1.6\%) (cerebral hemorrhage related to hyperperfusion disorder: two patients and cerebral infarction related to vascular dissection: one patient) in the early phase. In the late phase, minor stroke was observed in two patients $(2.9 \%)$ (peripheral embolism: one patient and guidewire-perforation-related subarachnoid hemorrhage: two patients), and major stroke in one (in-stent thrombosis) (Table 2).

In the late phase, $\geq 50 \%$ restenosis was noted in 11 patients during the follow-up period: eight patients $(24.2 \%)$ who underwent balloon angioplasty and three $(8.5 \%)$ who underwent stenting. Recurrent cerebral infarction was observed in one patient and TIAs in two. In 8 of the 11 patients, additional treatment was performed (Wingspan stent insertion: six patients and balloon angioplasty: two patients).

\section{Discussion}

In Japan, a balloon catheter for stenotic intracranial blood vessels was approved in 1991, earlier than in Europe and the United States. However, the catheter initially had a single lumen, and the incidence of perioperative complications was high. The results of treatment were not always favorable. In 2002, a double-lumen balloon catheter for intracranial blood vessels was approved, and stent-free balloon angioplasty has since been primarily selected in Japan. The reported incidence of perioperative complications related to minimally invasive procedures is relatively low, whereas that of restenosis is high [5, 6]. However, there are no data to prove the efficacy of endovascular treatment for patients with symptomatic intracranial stenosis so far.

In the United States, the Wingspan stent for intracranial stenosis was approved by the FDA in 2005. In 2011, a randomized, controlled study (SAMMPRIS) of vasodilation with a self-expandable-type stent for intracranial blood vessels, the Wingspan stent (Stryker, U.S.A.), which was newly developed to treat symptomatic intracranial artery stenosis, reported positive medical outcomes [7]. The subjects were 451 patients with $\geq 70 \%$ stenosis with an interval of $\leq 1$ month from the onset of TIA or mild cerebral infarction. Primary endpoints were stroke and death within 30 days. In the medical treatment and stenting groups, their incidences were 
$5.8 \%$ and $14.7 \%$, respectively, demonstrating a significant difference. Regarding perioperative complications, the incidence of ischemic stroke was $10.2 \%$ and that of hemorrhagic stroke was $4.5 \%$. Among ischemic complications, penetrating-vessel-infarction-associated complications were observed in 15 patients $(6.7 \%)$, embolic-infarction-associated complications in six $(2.7 \%)$, and stent thrombosis in two $(0.9 \%)$ [8]. As etiological factors for the complications, the use of a thick, hard delivery system was indicated, and patients treated in the acute to subacute phases after the onset of cerebral infarction were included. On the other hand, the recurrence rate $\geq 30$ days after treatment in the two groups was approximately $5.8 \%$, demonstrating no difference. In addition, the long-term results of the SAMMPRIS trial suggested no significant difference in the incidence of new ischemic events after the perioperative period between the stenting and medical treatment groups [9].

In the United States, the Wingspan stent was initially indicated for drug-therapy-resistant patients with $\geq 50 \%$ stenosis and ischemic cerebrovascular disorder, including TIA, related to intracranial artery stenosis. However, after 2008, the indication criteria were strictly modified based on the results of the SAMMPRIS trial: $\geq 70 \%$ stenosis, resistance to drug therapy, a history of $\geq 2$ strokes, excluding TIA, and an interval of $\geq 8$ days from onset. Regarding stenting with a Wingspan stent for stenosis of the middle cerebral artery, the reported incidence of complications was high in the learning stage, whereas there was a $50 \%$ decrease in the incidence in the acquired stage $[10,11]$.

Intracranial angioplasty with stenting initially started using the coronary balloon-mounted stents. A recent multicenter registry study recruiting 300 patients demonstrated that the 30-day rate of stroke, TIA, and death after intracranial stenting with a balloon-mounted coronary stent or the Wingspan stent was $4.3 \%$. Patients treated with a balloonmounted stent were less likely to have MCA stenosis and had a lower degree of residual stenosis than the Wingspan stent. However, a randomized clinical trial (the Vitesse intracranial stent study for ischemic stroke therapy: VISSIT), which compared balloon-expandable stent treatment with medical therapy in symptomatic intracranial stenosis, indicated that the 30-day primary safety end point occurred in more patients in the stent group $(24.1 \%)$ than in the medical group (9.4\%) [12].

Both SAMMPRIS and VISSIT trials were not able to establish the efficacy of intracranial artery stenting compared with medical treatment. A SAMMPRIS post hoc analysis failed to show any subgroup of patients with intracranial artery stenosis who significantly benefited from stenting, even those at particularly high risk of stroke on aggressive medical therapy. Further clinical trials may consider selection of patients demonstrating hemodynamic compromise as the mechanism of their ischemic stroke related to intracranial artery stenosis.
In addition, balloon angioplasty without stenting technique may be another effective option for the treatment.

Our study has several limitations. This is a small retrospective study in which bias may have been introduced in the selection of patients and lack of medical arm. Other limitations are the single-center design of study, insufficient follow-up data, and only Japanese population data. Angiographic follow-up was usually performed once at 6 months after the procedure and MRA was performed mainly after that. Finally, this study consists of the experience of operators in an academic hospital, which may limit the generalizability of our results.

Balloon angioplasty and stenting for patients who have symptomatic intracranial atherosclerotic stenosis may have the potential of better clinical outcome if patients are properly selected and treated by an experienced operator at a high-volume center. However, prospective studies with a large population and long follow-up should be done to evaluate the conclusion. Furthermore, well-designed randomized controlled trials will be necessary to show the value of endovascular treatment (when compared to medical treatment) for patients with symptomatic intracranial atherosclerotic stenosis.

\section{References}

1. White H, Boden-Albala B, Wang C, Elkind MS, Rundek T, Wright CB (2005) Ischemic stroke subtype incidence among whites, blacks, and Hispanics: the Northern Manhattan Study. Circulation 111:1327-1331

2. Kobayashi S (2015) Stroke data bank in Japan 2015. Nakayama Shoten, Tokyo

3. Gomez CR, Orr SC (2001) Angioplasty and stenting for primary treatment of intracranial arterial stenoses. Arch Neurol 58:1687-1690

4. Connors JJ III, Wojak CC (1999) Percutaneous transluminal angioplasty for intracranial atherosclerotic lesions: evolution of technique and short-term results. J Neurosurg 91:415-423, 1999

5. Ueda T, Takada T, Nogoshi S, Yoshie T, Takaishi S, Fukano T (2018) Long-term outcome of balloon angioplasty without stenting for symptomatic middle cerebral artery stenosis. J Stroke Cerebrovasc Dis 27(7):1870-1877

6. Mazighi M, Yadav JS, Abou-Chebl A (2009) Durability of endovascular therapy for symptomatic intracranial atherosclerosis. Stroke 39:1766-1769

7. Chimowitz MI, Lynn MJ, Derdeyn CP, Turan TN, Fiorella D, Lane BF, Janis LS, Lutsep HL, Waters MF, Hoh BL, Hourihane JM, Levy EI, Alexandov AV, Harrigan MR, Chiu D, Klucznik RP, Clark JM, McDougall CG, Johnson MD, Pride GJ Jr, Torbey MT, Zaidat OO, Rumboldt Z, Cloft HJ (2011) Stenting versus aggressive medical therapy for intracranial arterial stenosis. N Engl J Med 365:993-1003

8. Derdeyn CP, Fiorella D, Lynn MJ, Rumboldt Z, Cloft HJ, Gibson D, Turan TN, Lane BF, Janis LS, Chimowitz MI (2013) Mechanisms of stroke after intracranial angioplasty and stenting in the SAMMPRIS trial. Neurosurgery 72(5):777-795

9. Derdeyn CP, Chimowitz MI, Lynn MJ, Fiorella D, Turan TN, Janis LS, Montgomery J, Nizam A, Lane BF, Lutsep HL, Barnwell SL, 
Waters MF, Hoh BL, Hourihane JM, Levy EL, Alexandov AV, Harrigan MR, Chiu D, Klucznik RP, Clark JM, McDougall CG, Johnson MD, Pride GJ Jr, Lynch JR, Zaidat OO, Rumboldt Z, Cloft HJ (2014) Aggressive medical treatment with or without stenting in high-risk patients with intracranial artery stenosis (SAMMPRIS): the final results of a randomized trial. Lancet 383:333-341

10. Wang ZL, Gao BL, Li TX, Cai DY, Zhu LF, Xue JY (2016) Outcomes of middle cerebral artery angioplasty and stenting with Wingspan at a high-volume center. Neuroradiology 58:161-169
11. Gao P, Wang D, Zhao Z, Cai Y, Li T, Shi H (2016) Multicenter prospective trial of stent placement in patients with symptomatic highgrade intracranial stenosis. AJNR Am J Neuroradiol 37:1275-1280

12. Zaidat OO, Fitzsimmons BF, Woodward BK, Wang Z, KillerOberpfalzer M, Wakhloo A et al (2015) Effect of a balloonexpandable intracranial stent vs medical therapy on risk of stroke in patients with symptomatic intracranial stenosis. The VISSIT randomized clinical trial. JAMA 313(12):1240-1248

Open Access This chapter is licensed under the terms of the Creative Commons Attribution 4.0 International License (http://creativecommons. org/licenses/by/4.0/), which permits use, sharing, adaptation, distribution and reproduction in any medium or format, as long as you give appropriate credit to the original author(s) and the source, provide a link to the Creative Commons license and indicate if changes were made.

The images or other third party material in this chapter are included in the chapter's Creative Commons license, unless indicated otherwise in a credit line to the material. If material is not included in the chapter's Creative Commons license and your intended use is not permitted by statutory regulation or exceeds the permitted use, you will need to obtain permission directly from the copyright holder. 